Document downloaded from:

http://hdl.handle.net/10251/154380

This paper must be cited as:

Mora Navarro, JG.; Femenia-Ribera, C.; Martínez Llario, JC.; Antequera Terroso, EB.

(2018). Optimising urban routes as a factor to favour sustainable school transport. Journal of Transport Geography. 72:211-217. https://doi.org/10.1016/j.jtrangeo.2018.09.001

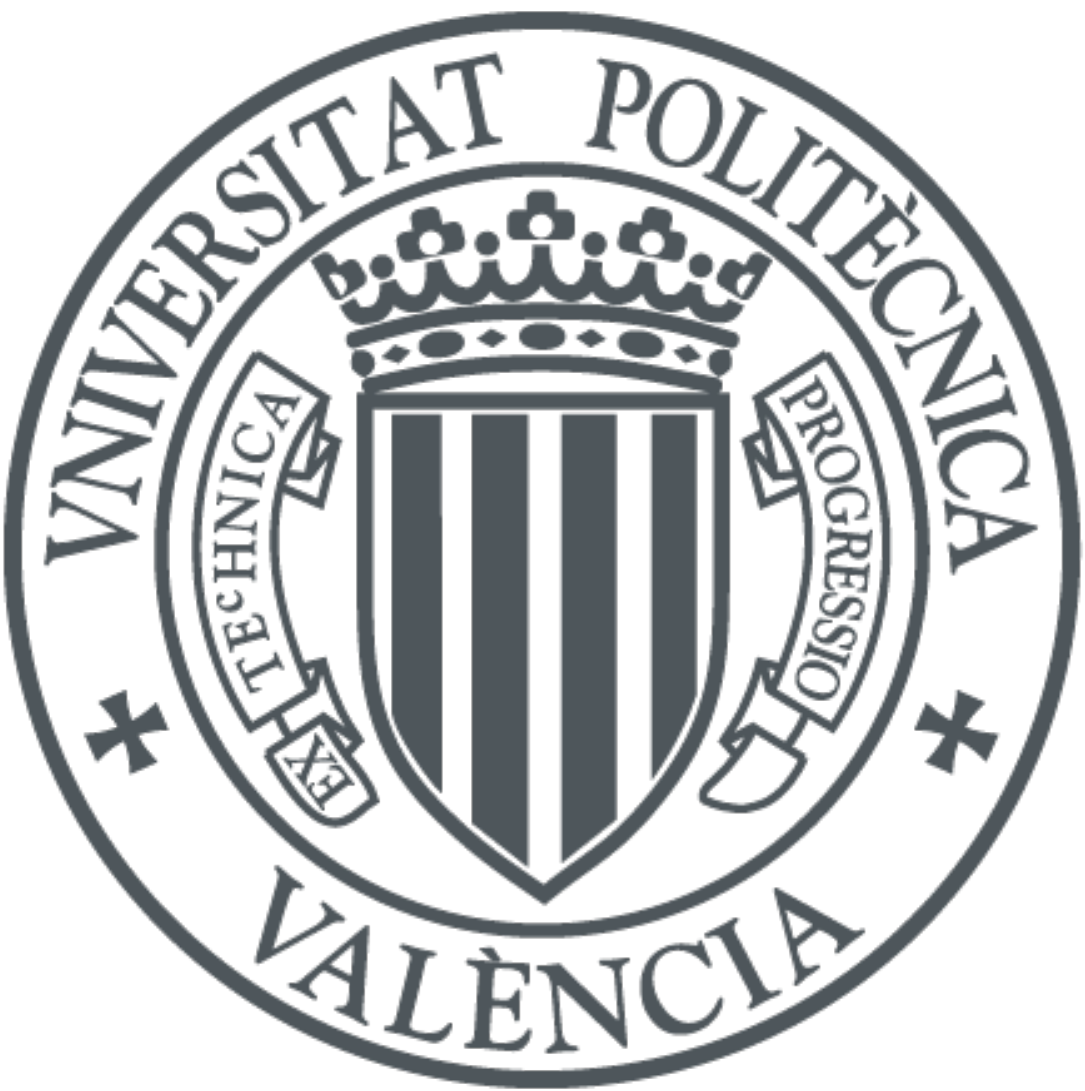

The final publication is available at

https://doi.org/10.1016/j.jtrangeo.2018.09.001

Copyright Elsevier

Additional Information 


\title{
OPTIMISING URBAN ROUTES AS A FACTOR TO FAVOUR SUSTAINABLE SCHOOL TRANSPORT
}

Gaspar Mora-Navarro ${ }^{\mathrm{a}}$, Carmen Femenia-Ribera ${ }^{\mathrm{a}}$, Jose Martinez-Llario ${ }^{\mathrm{a}}$, Enrique Antequera-Terroso ${ }^{\mathrm{b}}$

${ }^{a}$ Department of Cartographic Engineering, Geodesy and Photogrammetry, Universitat Politècnica de València, Camino de Vera, s/n, Valencia 46022, Spain

${ }^{b}$ Department of Urban Planning, Universitat Politècnica de València, Camino de Vera, s/n, Valencia 46022, Spain

\begin{abstract}
:
Finding an optimum route on foot or by bicycle between two points in a city is no simple task. For each person the optimum route may differ according to the time they have or to their physical condition. Nowadays with vast amounts of readily available geographic data, it is possible to calculate huge quantities of types of routes that differ from the shortest one. This work presents different geoportal examples that calculate several types of routes, and optimum routes according to distinct criteria. Cartography and algorithms are detailed, which enable routes to be obtained.
\end{abstract}

This work presents the stretch comfort concept. Unlike walkability, which refers to an area, stretch comfort refers to a footpath stretch. To calculate the comfort of each stretch, it is necessary to have detailed data of footpaths. The optimum route is calculated according to the comfort of footpath stretches, and the resulting route can cross different areas with a distinct walkability.

One practical case is presented, carried out in the town of Alginet, near Valencia (Spain). The project consists in a geoportal that calculates the most accessible and comfortable routes, devised to encourage walking across this town (http://upvusig.car.upv.es/algired-en/). The geoportal algorithms models the factors that parents consider important to transport their children to school on foot, according to a survey. The geoportal calculates two routes, the shortest and the most comfortable. Both routes are drawn on a map of the town to be compared between them. The 
most comfortable routes are about 4 minutes slower, but include wider footpaths, roads with less traffic and more trees and zebra crossings, and they also take into account traffic lights.

The project acted as a basis to help the Alginet Town Council choose and adapt several pedestrian routes to encourage children to walk to school and back. A second survey shows than $33 \%$ of parents take their children to school on foot more frequently.

\section{Keywords:}

Routes; geoportal; pedestrian; walkability; school

\section{Introduction}

As the population grows the current trend is for people to concentrate in cities, while rural areas become less populated. The urban area is estimated to multiply by 3 in 2030 (Seto et al., 2011). Most citizens need to move around the city on a daily basis, and many choose a private car as their means of transport. This causes air pollution problems and greenhouse gas emissions in cities.

Authorities are increasingly taking measures to accomplish healthier cities by encouraging people to active transportation; that is, to travel by bicycle or on foot. As the authorities are extending bike lane networks, this means that using bicycle-sharing systems is increasingly extending, just as many studies about fuel savings, pollution, effects on health and the risks of moving around the city on a bicycle have shown (de Hartog et al., 2010; Faghih-Imania and Elurub, 2015; Frade and Ribeiro, 2015; García-Palomares et al., 2012). Together bicycle-sharing systems, cycling web route planners (Su et al., 2010) and studies that analysed the factors that influence choice of route (Broach et al., 2012; Ehrgott et al., 2012; Rybarczyk and Wu, 2010) have started to appear.

An important parameter to take in account in this issue is walkability. Walkability is the degree to which the built environment supports the possibility of individuals engaging in active transportation in one area of a city (e.g. walking, biking) (Howell et al., 2017). There are several city walkability indices, all of which correlate with active transportation behaviours (Walkability 
Index, Walk Score ${ }^{\circledR}$, Walkability Scale, etc.). The Walkability Index, henceforth referred to as walkability, is the most popular (Lefebvre-Ropars et al., 2017). To obtain an area's walkability, the following parameters are considered: land use mix, street connectivity, residential density and retail intensity (Poulsen et al., 2018).

The online Walk Score ${ }^{\circledR}$ Calculator (Walk Score ${ }^{\circledR}$, n.d.) is being used to plan research and in applications to measure the walkability of an address (Aston et al., 2016; Hall and Ram, 2018). This index assesses the walking potential of a place by combining three elements: the shortest distance to a group of preselected destinations, block length, and the intersection density around the origin. Higher Walk Scores indicate that neighbourhoods are more walkable, and residents are closer to transit and activity opportunities (e.g. commercial, recreational, etc.) (Akbari et al., 2018).

A relevant factor that can tip the balance when it comes to choosing motorised transport or travelling by bicycle or on foot is the number of trees along the route because this increases pedestrian comfort (Takebayashi et al., 2017). Apart from purifying air, trees improve the city’s aesthetics (Lothian, 1999) and, conversely to popular belief, trees even lower the incidence of asthma in children (Dales et al., 2008). Trees in natural spaces in cities, like parks and greenbelt areas, benefit human health (Frumkin, 2001), and may even benefit children's social, emotional and behavioural development (Richardson et al., 2017). Citizen accessibility to green spaces is the object of many studies (Fan et al., 2017; Žlender and Ward Thompson, 2017). Quantifying the number of trees, and their vigorousness, is important. The number of trees is a factor that the present work takes into account. Many types of telematic techniques are available to count the number of trees, such as orthophotographs, remote sensing, LIDAR, and even imagery and computer vision (Recio et al., 2013; Seiferling et al., 2017).

Accessibility is a crucial factor that comes into play when choosing a means of transport or travelling on foot or by bicycle around a city; e.g., the ease with which we can move around a city. Accessibility is determined by the elements that we come across on our way (built environment), such as footpaths, zebra crossings, pedestrian zones, traffic lights, bicycle lanes, parks, greenbelt areas, squares, etc. Previous studies have attempted to correlate the built environment with walking or biking as a means of transport in the city (Panter et al. 2008; Wong 
et al. 2011; Etman et al. 2014; Cerin et al. 2017). These studies conclude that citizens positively evaluate their moving around the city being easy and offering connectivity, short routes and safety. Two highlighted factors are the availability of zebra crossings and parallel parking. The more zebra crossings and the less parallel parking, the more likely people will decide to walk or ride a bicycle (de Vries et al., 2010). Reduced parking availability creates a disincentive for using automobiles. A policy implication derived from this is that authorities should not prioritise expanding parking facilities if their main objective is to improve walk access for residents to schools, rail stations, bus stations, etc. (Akbari et al., 2018).

A very important accessibility factor is slopes because they are very limiting for people with reduced mobility, or who use wheelchairs or push prams. Steep slopes make upward pedestrian movements difficult, and downward movements can be hazardous. A slope is a highly relevant factor even for calculating routes for vehicles because they significantly increase the amount of fuel employed (Lorente-Sánchez et al., 2016).

Another important element that affects our choice of means of transport is traffic on streets. Studies suggest that children avoid walking or cycling along busy roads on their way to school (Krenn et al., 2014).

Conversely, however, other studies have not been able to relate characteristics on school routes (built environment) with the routes chosen to go to school, and have found that the only factor that correlates with not using a car is a short route (Wong et al., 2011).

Finding an optimum root on foot or by bicycle between two points in a city is no simple task. For each person, the optimum route may differ depending on the time, their physical condition or preferences. Nowadays with vast amounts of readily available geographic data, it is possible to calculate huge quantities of types of routes that differ from the shortest one; for instance, the most accessible route may be where a slope or the minimum footpath width is limited. A more comfortable route can also be obtained according to each user's preferences at a given time, who might wish to avoid areas in the city with higher pollen density, noisier places, or wish to seek shade because it is very hot. Some pedestrians may prefer streets with either more trees or 
monuments. Obtaining routes becomes less evident as the city grows in size because the variables to bear in mind also grow.

According to the literature, the pedestrians who wish to walk prefer routes that include pedestrian zones and good facilities for crossing streets, such as traffic lights or zebra crossings, junctions (Anciaes and Jones, 2018; de Vries et al., 2010), tree-lined streets (Takebayashi et al., 2017), which are not very noisy and are free of heavy traffic (Ehrgott et al., 2012; Krenn et al., 2014), as well as short routes (Wong et al., 2011). Therefore, we conducted a survey with the parents of primary schoolchildren that asked them about their preferences for walking to school. The thesis of this research is: if users can calculate more pleasurable routes around the city, they will be encouraged to travel more on foot, which will help improve users' health status and the city itself. This work shows a geoportal in which more comfortable routes are calculated according to pedestrian preferences.

\section{General process to calculate optimum routes}

Calculating routes involves a significant cartographic work component. First of all, it is necessary to obtain network stretches and ensure that the network topology is correct. Network stretches define the lines where access is available. Topology is defined as the spatial relation of some objects with others: connected, indoors, outdoors, overlapping, etc. For networks, a correct topology means that stretches are properlly connected to one another, and stretches must divide on crossings with two stretches or more. The stretches that must be passed via tunnels or bridges can cross other stretches without being divided. The end points of stretches are known as nodes (Figure 1).

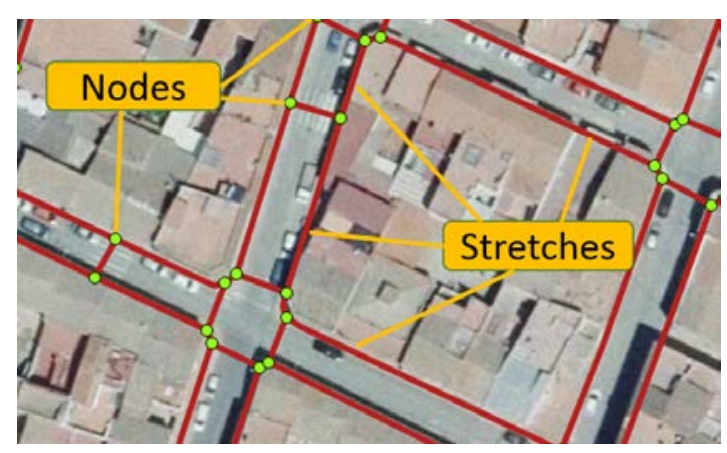


Figure 1: Stretches network and nodes.

With networks for pedestrians, users can move around by walking in both directions in all stretches. However, some networks include stretches that can be walked around in only one direction; i.e., moving in one direction is not the same as moving in another direction. In such cases, it is necessary to bear in mind the direction that each stretch is drawn or digitalised in (Figure 2).

Once the network is topographically correct, the next step is associate a cost, also called an impedance cost, to each stretch (Figure 2). In some cases, moving over a stretch in one direction can incur a different cost than it would in the opposite direction; e.g., if there is a downward slope because, depending on the application, the cost can be much less than moving through the stretch in an upward direction. So such applications include two costs per stretch, one in each digitalisation direction.

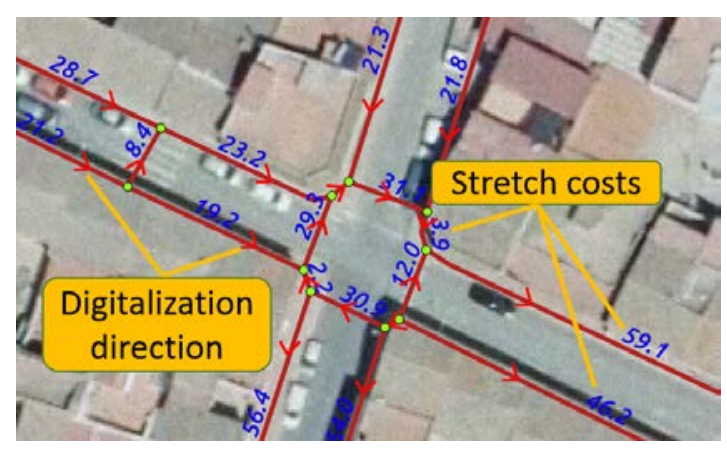

Figure 2: Stretch costs.

Once we have the network and know the costs of each stretch, an algorithm capable of locating the series of connected stretches that leads from one network point to another is needed, and in such a way that the sum of the total costs of all stretches is minimum. This is a so-called optimum route. Several algorithms exist to calculate optimum routes: Floyd-Warshall's, Johnson, A-star or Dijkstra. A-star algorithm performs well in networks with many edges. It is widely used to calculate optimised routes (Wei and Xiaoguang, 2013).

The main difficulty lies in calculating the costs of each stretch. The first step consists in deciding which variables are to be considered, a decision that depends on the application. The most important factor to calculate routes for private cars is the time taken to travel each stretch, where 
time represents the cost field in this case. The cost will, therefore, depend on the maximum speed of each stretch, traffic, the number of junctions, etc. When attempting to calculate the optimum route for pedestrians who wish to walk, the factors that need to be considered to calculate the costs of each stretch completely differ.

Calculating the cost of all the directions of each stretch is the most important task. This cost considers the variables needed for each route type, and each variable is also weighted so that it has a stronger or weaker influence on the final cost. Normally, the cost of stretches depends on stretch length. What the variables do is to amend stretch length in such a way that, if the value of the variable is positive for the pursued purpose, length will be artificially subtracted from the stretch, and vice versa if the variable takes a negative value. The calculation system seeks a combination of stretches with a minimum total cost sum. Thus the cheapest stretches are those with the most favourable conditions for route type, which are more frequently selected. For example, if the intention is to seek the most comfortable routes for pedestrians, the number of trees on footpaths, noise, traffic intensity, etc., can be taken into account.

The three variables influence how comfortable each stretch is, and they must be combined in a formula to calculate the cost so that the influence of each variable is suitable. For instance, (1) could be used:

$$
\text { Cost }=\text { Length } *(1+\text { NoiseFactor }+ \text { TrafficFactor })-2 * \text { TreeNumber }
$$

Depending on the noise value, the stretch penalisation factor could lie between 0 and 0.5; e.g., and the same applies to the traffic factor. The noise and traffic factors increase the stretch cost, which makes its choice more difficult. The number of trees, however, lowers the stretch cost. This simple formula combines the three factors considered to calculate the cost of stretches. Logically, the hard part is calibrating the influence of each factor so that the calculated route properly reflects the desired route type. The formula (1) is an example that illustrates how to model a simple problem with only three factors: noise, traffic and number of trees. The example shows that depending on the weight assigned to each factor, the stretch cost changes and, therefore, the optimum path can be totally different. The question is finding in each case the formula and factors that better model the problem to be solved. To check the different model 
versions, the method generally used is to compare the obtained optimum path, which is longer than the shortest path, with the shortest path. With Formula (1) the check will consist in testing if the reduction in total noise, total traffic and the increase in the number of trees in the optimum path are attractiveg enough. The optimum path must be attractive to encourage users to walk more, and to spend more time choosing the optimum and longer path instead of the shortest path. If the optimum path is too long, very few people will use it since length is a crucial factor for users (Wong et al., 2011). If the idea is to obtain healthy optimal routes for users, as in this example, it is necessary to strike the length-attractiveness balance. The goal of this calibration is to find optimal routes with real possibilities of being chosen by users. This must be done by pondering the factors in the formula that model the optimum paths.

In many cases, the values of the variables to be considered are not always constant, but depend on time and on the day of the week. In the previous example, doubtlessly traffic intensity and noise level strongly depend on the time and the week day. We can consider entertainment areas, bars and discos at weekends, at nighttime and in same area on a Monday morning. The temporal component can also be considered when calculating the route because it may have a different cost for, e.g., each hour of the day, and the value of this cost is used depending on the time when the user calculates this route. These are dynamic environments. To solve the optimal route in a dynamic environment, it is necessary to have a model that relates the stretch cost and time. One example is emergency management, where road conditions can rapidly change (Shahabi and Wilson, 2018).

\subsection{Examples of optimum routes}

An example of a geoportal to calculate routes to encourage travelling by bicycle or on foot is found in the city of Valencia in the Healthy Routes Project (Green Urban Data, n.d.). The Healthy Routes Project contains four route types (Levante-EMV, 2017a):

- Routes with fewer allergens, where the calculated route avoids areas with more pollen. This factor can be calculated thanks to the Valencia City Council publishing maps with the city's pollen data. 
- Less noisy routes. The city of Valencia publishes noise maps at different times of the day. This allows a noise factor to be calculated, which can be associated with network stretches.

- More shaded routes. In Valencia, summer temperatures can easily exceed $30^{\circ} \mathrm{C}$, so walking in the shade is a very important factor. To calculate the shade that buildings project on streets, a digital model of buildings is required. To calculate the shade projected on the ground, we need to know the sun's position, which depends on the day and time to calculate the route. Digital models of elevations can be obtained with LIDAR (Laser Imaging Detection and Ranging) data, which are free data for Valencia. Knowing the sun's position and building heights allows a shade map to be calculated, and to associate an amount of shade with each stretch.

- Routes that offer better quality urban environment quality. These routes consider the city's forest mass and vigorousness of plants. These indices are obtained by remote sensing techniques, satellite images. Many satellite images are free; e.g., those taken by satellite Landsat 8 with a frequency of 16 days, and those taken by satellites Sentinel 1, 2 and 3, obtained every 5 days.

The formulae applied to model the cost of each network stretch are the most important ones to calculate the optimum route, but can be complex. In Lorente-Sánchez et al. 2016, routes are calculated that minimise the diesel used by lorries which transport olives from the place they are collected to an olive press. The system calculates the route to the olive press, which involves using less diesel, and there may be a different olive press to the nearest one. To calculate diesel use, the COPERT (Computer Program to calculate Emissions from Road Traffic) model was employed. COPERT is a model developed by the European Environment Agency to estimate vehicle emissions (Broderick, 2007). The COPERT model takes into account the weight of loads, speed and any slopes on the route. Once again, free data are used: cadastral cartography, Open Street Map data, and LIDAR data to calculate the slopes along stretches using the digital model. 


\section{Practical case. Calculating comfortable routes to schools in} Alginet

As a practical application, we ran a project to calculate comfortable routes using a network of footpaths in the town of Alginet, near Valencia in east Spain. The aim was to encourage parents to take their children to school on foot rather than resorting to driving them in private cars.

\subsection{The town of Alginet}

To be able to understand the conducted research, it is important to have an idea of the characteristics of the town of Alginet (http://www.alginet.es). Alginet is located in the province of Valencia, east Spain, and lies about $23 \mathrm{~km}$ south of the city of Valencia, the capital city of the province. The town's economy has traditionally been agriculture. It covers a surface area of some $24 \mathrm{~km}^{2}$, and it has slightly more than 13,000 inhabitants. Regarding orography, we stress that the town is practically flat, which means that slopes are barely noticed. The average Walk Score for Alginet in its urban area is 80 out of 100. According to this index, Alginet is classified as very walkable.

This town has three public and one private childhood and primary education schools, one municipal nursery school and one secondary education institute. The childhood and primary education schools provide compulsory schooling to all children aged 3-11 years.

\subsection{Background}

Developing this comfortable routes project for schoolchildren came from the ideas of some tasks performed by the Vicente Blasco Ibáñez School. This school has the most schoolchildren in the town, about 430. The Vicente Blasco Ibáñez School forms part of the project My Smart School (https://www.up2europe.eu/european/projects/my-smart-school_85778.html), financed by European programme Erasmus+ (http://ec.europa.eu/programmes/erasmus-plus). My Smart School is a transnational project of strategic associations financed by the EU, in which the primary education Vicente Blasco Ibáñez School participates, along with the Alginet Town 
Council, and other Spanish, French and Italian schools. The idea arose to encourage schoolchildren to walk to school and back as safely and comfortably as possible.

The comfortable routes calculation project began by sending a survey to the parents of the schoolchildren who went to the Vicente Blasco Ibáñez School for them to indicate with free answers the four characteristics that access to school must have to make travelling by bicycle or on foot better. There were 25 responses, and each had four characteristics. Table 1 shows some responses that could be grouped.

\begin{tabular}{|l|l|}
\hline Item & $\begin{array}{l}\text { No. of times } \\
\text { mentioned }\end{array}$ \\
\hline Marked routes on a thoroughfare & 14 \\
\hline Wide well-maintained footpaths & 12 \\
\hline Bicycle lane available & 12 \\
\hline Police around when entering/leaving school & 10 \\
\hline More zebra crossings & 9 \\
\hline Stopping traffic when entering/leaving school & 6 \\
\hline Light traffic & 6 \\
\hline Places available to park bicycles & 3 \\
\hline Better traffic signs & 2 \\
\hline More traffic lights & 2 \\
\hline
\end{tabular}

Table 1: Survey results about important items about transport to school on foot or by bicycle. Source: the Authors using the data collected with the survey conducted as part of the My Smart School project

According to the survey, having the following available to walk to school with children is important: wide footpaths, police watching, zebra crossings, light traffic, traffic lights and good road signs of the route to be followed. Many of these elements mentioned by parents can be 
mapped and be included in a system to calculate routes. In this way the calculated routes adapt to parents’ preferences, which would encourage children to walk to school and back.

The survey results show that parents’ preferences coincide with the studied bibliography, except for trees. However, studies show that trees are an important factor for choice of route (Takebayashi et al., 2017) and have positive effects on human health (Dales et al., 2008; Frumkin, 2001; Lothian, 1999; Richardson et al., 2017). Thus the number of trees on streets was considered a favourable factor for calculating the routes in this research.

\subsection{Modelling comfortable routes for Alginet}

To model parents’ preferences, all the axes of the footpaths, zebra crossings and traffic lights on the streets were digitalised. The mean and minimum widths were obtained from each footpath stretch. The trees on each stretch were also counted. To obtain these data, orthophotographs from the National Aerial Orthophotography Plan were used, as were the Spanish cadastral cartography data, in a vector format, and visual inspections of the area were made. The statistics, obtained with the completed database, are shown and provide an idea of the town's built environment.

\begin{tabular}{|l|l|}
\hline Parameter & Value \\
\hline Number of trees & 1,625 \\
\hline Number of zebra crossings & 234 \\
\hline Total footpath length & $65,142 \mathrm{~m}$ \\
\hline Mean footpath width & $1.76 \mathrm{~m}$ \\
\hline Footpath length with a mean width below 1 m & $13,860 \mathrm{~m}$ \\
\hline Footpath length with a mean width over $1.5 \mathrm{~m}$ & $29,542 \mathrm{~m}$ \\
\hline
\end{tabular}

Table 2: The town's built environment parameters

The formula employed to model the most comfortable pedestrian route is (2): 


$$
\text { Cost }=(\text { StretchLength }-(\text { numTrees } * 2)) * \text { StretchType } * \text { TrafficIntensity }
$$

Where:

- StretchLength: stretch length

- numTrees: number of trees on the stretch

- StretchType: stretch type. Stretches are classified into six types:

o Zebra crossing with a traffic light. StretchType $=1.2$

o Zebra crossing with no traffic light. StretchType $=1.3$

o Minimum footpath width is $1 \mathrm{~m}$ wide and a mean width equal to or over $1.5 \mathrm{~m}$. StretchType $=0.8$

o Minimum footpath width is $1 \mathrm{~m}$ wide and a mean width below $1.5 \mathrm{~m}$. SectionType $=1$

o Minimum footpath width is under $1 \mathrm{~m}$. StretchType $=1.2$

o Road crossing with no zebra crossing. StretchType $=3$

- TrafficIntensity: Traffic intensity. Stretches are classified as four traffic intensities:

o Low. Traffic Intensity $=1$

o $\quad$ Medium. Traffic Intensity $=1.3$

o High. Traffic Intensity $=1.4$

o $\quad$ Very high. TrafficIntensity $=1.5$

The model was calibrated by testing different parameter values to strike a length-benefits equilibrium. The goal here is to find optimal routes with real possibilities of being chosen by users; that is, optimal routes that are not too much longer than the shortest routes. The next Chapter 3.4 presents an example in which it is possible to compare both routes.

On long streets with very few zebra crossings, stretches were created to cross the street on roads. The cost of these stretches is 3-fold higher than length, while the cost of crossing on a zebra crossing is 1.3-fold higher than length. This allows crossings to exist that are selected only if the cost of walking to a zebra crossing is very high, i.e., is far away, in an attempt to simulate human conduct. Let's remember that Alginet is a town with more than 10,000 inhabitants, it is flat, has 
light traffic on most streets, and very few streets allow two-way traffic. This means that citizens are often seen crossing streets without resorting to zebra crossings when they are too far away.

\subsection{Implementing Alginet's comfortable routes model in a geoportal}

The model is implemented into a PostgreSQL + PostGIS database. To calculate routes, the A-star algorithm is employed, which is available in the pgRouting extension of PostgreSQL. A geoportal was created (http://upvusig.car.upv.es/algired-en/) to make the calculation of routes easily available to users. Geoportals are suitable for making geographic information available to non-expert cartography users (Ganning et al., 2014; Resch and Zimmer, 2013).

All the geographical data were obtained from free public data, and all the software employed for development purposes were free open source software for geospatial applications, which is increasingly more reliable and competitive (Brovelli et al., 2017; Sui, 2014).

Two routes can be calculated on the geoportal by selecting a starting point and an arrival point; the shortest and the most comfortable, depending on the proposed model. The geoportal shows both routes and a table that compares the characteristics of each route (Figure 3). Then users can compare them and, by knowing the time cost, and the rest of the characteristics from each one, they can decide which one to choose. 


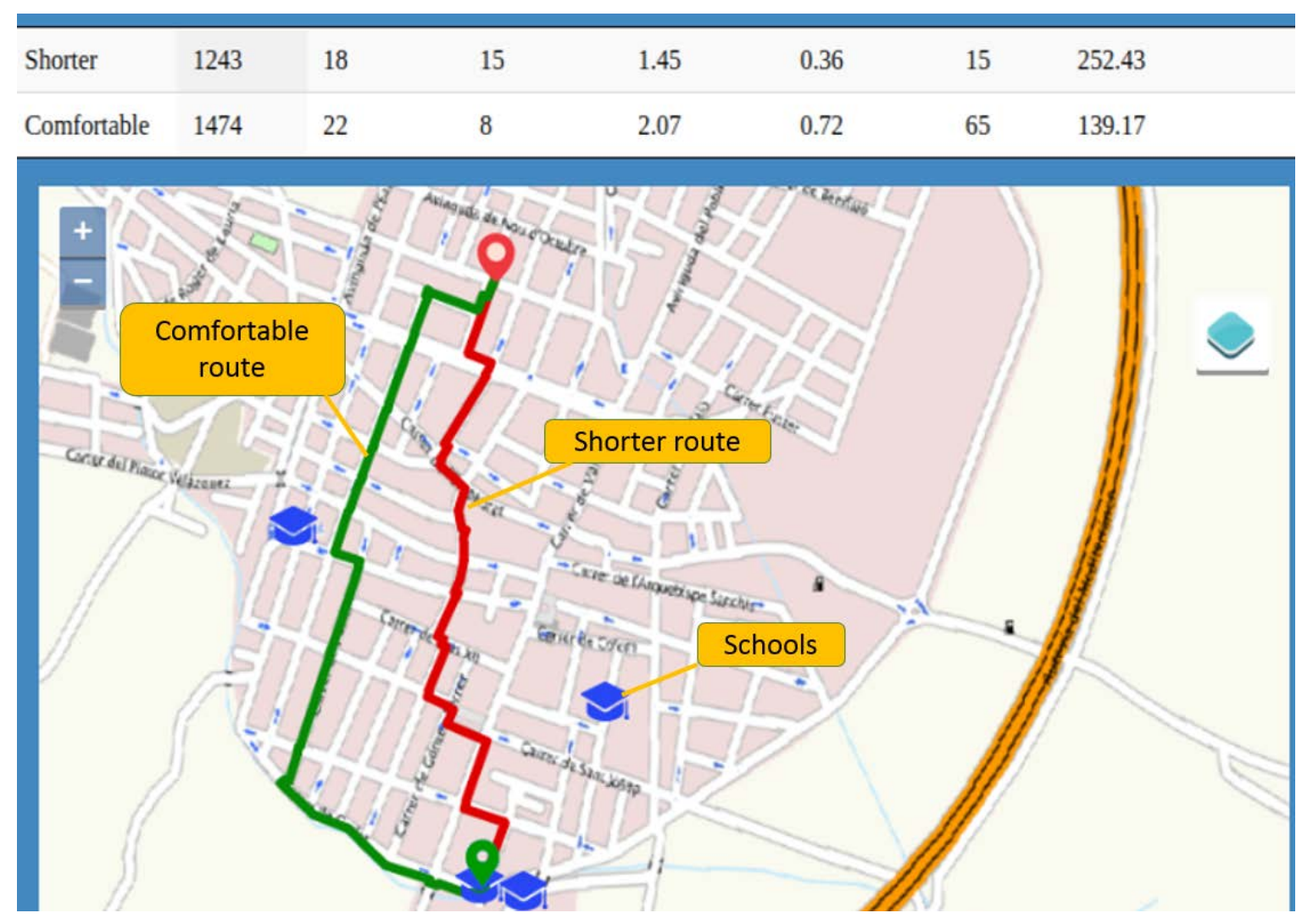

Figure 3: Walking route calculation example.

In Figure 3 we can see the difference between choosing one route or another. The most comfortable route has the drawback of taking 6 minutes longer, but has seven fewer crossings, the mean footpath width is $62 \mathrm{~cm}$ wider, the minimum footpath width is $36 \mathrm{~cm}$ wider, the route includes 50 more trees, and it involves walking $113 \mathrm{~m}$ less on streets with heavy traffic.

The comfort of each stretch can be obtained with the cost/stretch length ratio (3). If the cost is lower than the stretch length, then its factors are favourable.

$$
\text { Comfort }=\text { StretchLength } / \text { Cost }
$$

Unlike walkability, which refers to an area, stretch comfort refers to a footpath stretch. To calculate the comfort of each stretch, it is necessary to have detailed data about footpaths. The optimum route is calculated according to the comfort of footpath stretches, and the resulting route can cross different areas with a distinct walkability. 
Figure 4 shows a map on which the comfort of stretches is classified into five categories. This type of map can be used to plan, for instance, the choice of routes and their adaptation, or to make improvements at critical points of footpath networks.

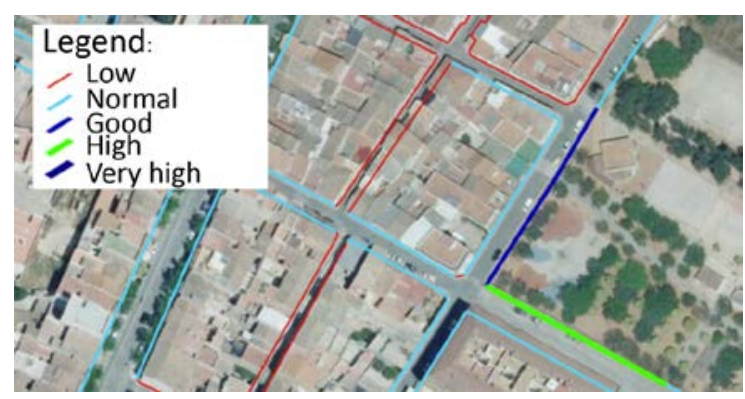

Figure 4: Footpath comfort classification.

The footpath comfort map (Figure 4), along with other maps with the values of the variables of each network stretch, are seen in the route-calculating geoportal.

\section{Alginet Town Council actions to encourage children to walk to school}

The data obtained by the geoportal to calculate routes and the comfortable footpath map were the basis used by the Alginet Town Council to design and adapt a series of routes around the town (http://www.alginet.es/a-peu-a-l-escola) (Figure 5).

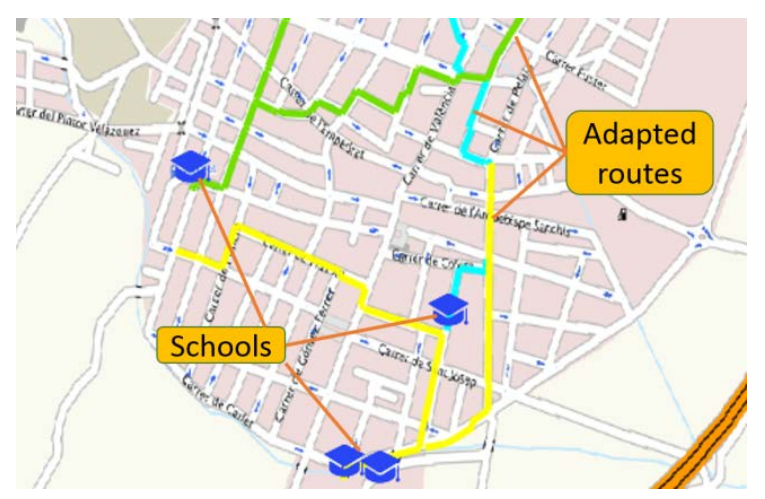

Figure 5: Adapted walking routes.

The geoportal created in this research shows 'Database data' in the menu option, the data of each stretch: footpath comfort, stretch cost, stretch length, stretch type (street crossing, footpath, or 
zebra crossing), minimum footpath with the average footpath width, number of trees and streets with intense traffic. By relying on this information, the Alginet Town Council chose three routes, and each one takes children to one school. The chosen routes were adapted to so that children can go to school on foot. This adaptation consisted in the Alginet Town Council signposting the routes using plaques and footmarks on the ground (Figure 6). Each route leads to a school, and each one has its associated colour. Marks are the route's colour so that children know the school that the route's colour takes them to. The Alginet Town Council increased the number of zebra crossings and improved a few footpaths at the accesses to schools. More police were placed in the areas with crossings among the routes when children entered and left schools.

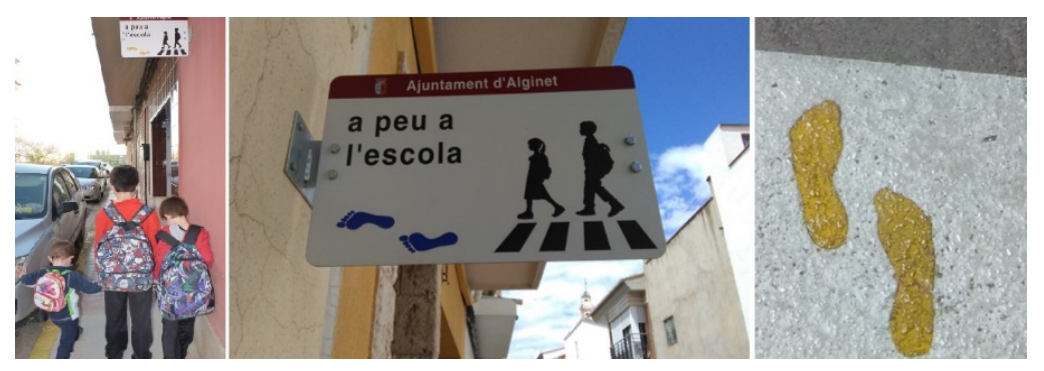

Figure 6: Adapted routes to school

With this routes design, and having improved their adaptation, the Alginet Town Council ran a campaign to encourage their use in the town's four childhood and primary education schools. This campaign was entitled: "A peu a l'escola/To school on foot”. This initiative was diffused by the Alginet Town Council and the schools diffused it to schoolchildren. Related news items are of interest and have been published in a local and provincial newspaper (Levante-EMV, 2017b).

Encouraging the use of school routes has also been highlighted in other nearby places, such as the city of Valencia (Zafra, 2017), and the towns of Algemesí (Levante-EMV, 2017c) or Almussafes (elperiodic.com, 2017).

\section{Description of the results obtained in Alginet}

Better adapting these routes has meant that the number of children who walk to school has increased slightly, as the survey conducted on the signposted routes shows. At the Vicente Blasco Ibáñez School in Alginet, once again a survey was conducted to know the degree of the 
increasing number of parents who take their children to school on foot. This survey contained five questions: six Yes/No-type questions. The obtained results are presented in the table below:

\begin{tabular}{|l|l|l|l|l|}
\hline \multirow{2}{*}{ Question } & \multicolumn{3}{|l|}{ Answered Yes } & \multicolumn{2}{l|}{ Answered No } \\
\cline { 2 - 6 } & Number & $\%$ & Number & $\%$ \\
\hline $\begin{array}{l}\text { Has/have your child/children informed you about the new } \\
\text { signposted routes to walk to school? }\end{array}$ & 175 & $81 \%$ & 40 & $19 \%$ \\
\hline $\begin{array}{l}\text { Did you know that the alginet Town Council has adapted and } \\
\text { signposted routes to walk to school? }\end{array}$ & 199 & $93 \%$ & 16 & $7 \%$ \\
\hline $\begin{array}{l}\text { Have these adaptations meant you walk your child/children } \\
\text { more frequently to school? }\end{array}$ & 70 & $33 \%$ & 145 & $67 \%$ \\
\hline $\begin{array}{l}\text { Do you know the geoportal for calculating routes to school? } \\
\text { http://upvusig.car.upv.es/algired-en/ }\end{array}$ & 53 & $25 \%$ & 162 & $75 \%$ \\
\hline If so, do you think the geoportal is useful? & 53 & $100 \%$ & & \\
\hline
\end{tabular}

Table 3: Survey on the use of the new adapted routes

As we can see from the survey results in Table 3, 33\% of parents answered that they took their child/children to school on foot more frequently, basically due to the adaptations made by the Alginet City Council. The adaptation works were practically limited to signposting and painting new zebra crossings. This means that from a small investment in signs, an advertising campaign and raising awareness among parents, a good percentage of parents positively reacted and encouraged their children to walk to school and back. Moreover, we observed that $100 \%$ of the people who knew the route-calculating geoportal found it useful.

\section{Conclusions}

If the routes to move between two points are optimum, they can increase the choice of travelling more healthily and ecologically, or can save time and fuel if vehicles are used. 
The quantity of open geographical data in standard formats helps facilitate and reduce costs of obtaining geographic data. GIS and geospatial databases allow complex analyses to be done to assign the influence of each geographical variable to each network stretch according to the selected model.

The results of the first survey conducted in this work to know which factors parents considered important for their children to walk to school generally coincided with the factors found in the literature.

The created route-calculating geoportal allows all the town's schoolchildren, from any Internet access, to identify a personalised, simple and safer route from home to their selected school.

The route-calculating geoportal also shows other maps that show the values of the cartographic variables of each stretch: mean and minimum widths, number of trees, comfort, etc. This enables urban planners to make decisions about improvements being made to adapt footpaths, and to select pedestrian routes.

The result of the comfortable route-calculating geoportal used herein was to adapt several routes to encourage more schoolchildren to go to school on foot, and also around the town. The Town Council also increased the presence of police at the busiest points, when people arrive at and leave schools.

As we can see from the survey results in Table 3, 33\% of the parents answered that they took their child/children to school on foot more frequently. We conclude that from a small investment in signs, an advertising campaign and raising awareness among parents, a good percentage of parents positively reacted and encouraged their children to walk to school and back.

Most probably the increasing number of parents that went to school on foot was due to the Alginet Town Council having conditioned the routes, but the route-calculation geoportal contributed to choose these routes. Currently, the geoportal is still being used with an average of 37 route calculations made a month after more than 1 year after the geoportal was set up.

The various examples of calculating the proposed routes stress that the optimum route between two points is not evident. An optimum route may depend on many spatial factors, which need to 
be obtained from maps, and correct combinations using an algorithm to calculate costs are necessary which model the system's performance.

\section{References}

Akbari, S., Mahmoud, M.S., Shalaby, A., Habib, K.M.N., 2018. Empirical models of transit demand with walk access/egress for planning transit oriented developments around commuter rail stations in the Greater Toronto and Hamilton Area. J. Transp. Geogr. 68, 1-8. doi:https://doi.org/10.1016/j.jtrangeo.2018.02.002

Anciaes, P.R., Jones, P., 2018. Estimating Preferences for Different Types of Pedestrian Crossing Facilities. Transp. Res. Part F Traffic Psychol. Behav. 52, 222-237. doi:https://doi.org/10.1016/j.trf.2017.11.025

Aston, L., Currie, G., Pavkova, K., 2016. Does transit mode influence the transit-orientation of urban development? - An empirical study. J. Transp. Geogr. 55, 83-91. doi:10.1016/j.jtrangeo.2016.07.006

Broach, J., Dill, J., Gliebe, J., 2012. Where do cyclists ride? A route choice model developed with revealed preference GPS data. Transp. Res. Part A Policy Pract. 46, 1730-1740. doi:https://doi.org/10.1016/j.tra.2012.07.005

Broderick, B., 2007. Spatial variation of roadside C2-C6 hydrocarbon concentrations during low wind speeds: Validation of CALINE4 and COPERT III modelling. Transp. Res. Part D Transp. Environ. 12, 537-547. doi:10.1016/J.TRD.2007.07.010

Brovelli, M.A., Minghini, M., Moreno-Sanchez, R., Oliveira, R., 2017. Free and open source software for geospatial applications (FOSS4G) to support Future Earth. Int. J. Digit. Earth 10, 386-404. doi:10.1080/17538947.2016.1196505

Cerin, E., Nathan, A., van Cauwenberg, J., Barnett, D.W., Barnett, A., 2017. The neighbourhood physical environment and active travel in older adults: a systematic review and metaanalysis. Int. J. Behav. Nutr. Phys. Act. 14, 15. doi:10.1186/s12966-017-0471-5

Chin, G.K., Niel, K.P., Giles-Corti, B., Knuiman, M., 2008. Accessibility and connectivity in 
physical activity studies: the impact of missing pedestrian data. Prev Med 46. doi:10.1016/j.ypmed.2007.08.004

Dales, R., Cakmak, S., Judek, S., Perzanowski, M.S., Rundle, A., 2008. Children living in areas with more street trees have lower prevalence of asthma. J. Allergy Clin. Immunol. 113, 303-306. doi:10.1016/J.JACI.2003.11.016

de Hartog, J.J., Boogaard, H., Nijland, H., Hoek, G., 2010. Do the health benefits of cycling outweigh the risks? Environ. Health Perspect. 118, 1109-1116. doi:10.1289/ehp.0901747

de Vries, S.I., Hopman-Rock, M., Bakker, I., Hirasing, R.A., van Mechelen, W., 2010. Built environmental correlates of walking and cycling in Dutch urban children: results from the SPACE study. Int. J. Environ. Res. Public Health 7, 2309-24. doi:10.3390/ijerph7052309

Ehrgott, M., Wang, J.Y.T., Raith, A., van Houtte, C., 2012. A bi-objective cyclist route choice model. Transp. Res. Part A Policy Pract. 46, 652-663. doi:https://doi.org/10.1016/j.tra.2011.11.015

elperiodic.com, 2017. Los alumnos del CEIP Almassaf señalizan las rutas seguras para ir al colegio. elperiodic.com.

Etman, A., Kamphuis, C.B., Prins, R.G., Burdorf, A., Pierik, F.H., Lenthe, F.J., 2014. Characteristics of residential areas and transportational walking among frail and non-frail Dutch elderly: does the size of the area matter? Int J Heal. Geogr 13. doi:10.1186/1476072X-13-7

Faghih-Imania, A., Elurub, N., 2015. Analysing bicycle-sharing system user destination choice preferences: Chicago’s Divvy system. J. Transp. Geogr. 44, 53-64. doi:10.1016/J.JTRANGEO.2015.03.005

Fan, P., Xu, L., Yue, W., Chen, J., 2017. Accessibility of public urban green space in an urban periphery: The case of Shanghai. Landsc. Urban Plan. 165, 177-192. doi:10.1016/j.landurbplan.2016.11.007

Frade, I., Ribeiro, A., 2015. Bike-sharing stations: A maximal covering location approach. 
Transp. Res. Part A Policy Pract. 82, 216-227. doi:10.1016/j.tra.2015.09.014

Frumkin, H., 2001. Beyond toxicity: Human health and the natural environment. Am. J. Prev. Med. 20, 234-240. doi:https://doi.org/10.1016/S0749-3797(00)00317-2

Ganning, J.P., Coffin, S.L., McCall, B., Carson, K., 2014. Goals, Challenges, and Capacity of Regional Data Portals in the United States: An Updated Understanding of Long-Standing Discussions. J. Urban Technol. 21, 125-139. doi:10.1080/10630732.2014.942168

García-Palomares, J., Gutiérrez, J., Latorre, M., 2012. Optimizing the location of stations in bike-sharing programs: A GIS approach. Appl. Geogr. 35, 235-246. doi:10.1016/J.APGEOG.2012.07.002

Green Urban Data, n.d. Healthy routes [WWW Document]. URL http://vps313983.ovh.net:3000/rutasverdes/ (accessed 2.23.18).

Hall, C.M., Ram, Y., 2018. Walk Score ${ }^{\circledR}$ and its potential contribution to the study of active transport and walkability: A critical and systematic review. Transp. Res. Part D Transp. Environ. doi:10.1016/j.trd.2017.12.018

Howell, N.A., Farber, S., Widener, M.J., Booth, G.L., 2017. Residential or activity space walkability: What drives transportation physical activity? J. Transp. Heal. 7, 160-171. doi:10.1016/j.jth.2017.08.011

Krenn, P.J., Oja, P., Titze, S., 2014. Route choices of transport bicyclists: a comparison of actually used and shortest routes. Int J Behav Nutr Phys Act 11. doi:10.1186/1479-5868-1131

Lefebvre-Ropars, G., Morency, C., Singleton, P.A., Clifton, K.J., 2017. Spatial transferability assessment of a composite walkability index: The Pedestrian Index of the Environment (PIE). Transp. Res. Part D Transp. Environ. 57, 378-391.

doi:https://doi.org/10.1016/j.trd.2017.08.018

Levante-EMV, 2017a. Una aplicación que diseña “rutas verdes” en València sin alérgenos ni ruidos. Levante-EMV. 
Levante-EMV, 2017b. Alginet habilita varias rutas peatonales para que los niños vayan a pie a la escuela. Levante-EMV.

Levante-EMV, 2017c. Algemesí mejorará el acceso peatonal a los colegios. Levante-EMV.

Lorente-Sánchez, S., Marqués-Mateu, Á., Mora-Navarro, G., 2016. Diseño de un geoportal web para el cálculo de costes de carburante en el transporte de la cosecha de aceituna, in: Asociación de Geógrafos Españoles (AGE) (Ed.), XVII Congreso Nacional de Tecnologías de Información Geográfica. Aplicaciones de Las Tecnologías de La Información Geográfica (TIG) Para El Desarrollo Económico Sostenible. Málaga (Spain), pp. 498-504. doi:ISBN: 978-84-940784-9-1

Lothian, A., 1999. Landscape and the philosophy of aesthetics: is landscape quality inherent in the landscape or in the eye of the beholder? Landsc. Urban Plan. 44, 177-198. doi:10.1016/S0169-2046(99)00019-5

Panter, J.R., Jones, A.P., Sluijs, E.M., 2008. Environmental determinants of active travel in youth: a review and framework for future research. Int J Behav Nutr Phys Act 5. doi:10.1186/1479-5868-5-34

Poulsen, M.N., Knapp, E.A., Hirsch, A.G., Bailey-Davis, L., Pollak, J., Schwartz, B.S., 2018. Comparing objective measures of the built environment in their associations with youth physical activity and sedentary behavior across heterogeneous geographies. Heal. Place 49, 30-38. doi:10.1016/j.healthplace.2017.11.003

Recio, J.A., Hermosilla, T., Ruiz, L.A., Palomar-Vázquez, J., 2013. Automated extraction of tree and plot-based parameters in citrus orchards from aerial images. Comput. Electron. Agric. 90, 24-34. doi:10.1016/J.COMPAG.2012.10.005

Resch, B., Zimmer, B., 2013. User Experience Design in Professional Map-Based Geo-Portals. ISPRS Int. J. Geo-Information 2, 1015-1037. doi:10.3390/ijgi2041015

Richardson, E.A., Pearce, J., Shortt, N.K., Mitchell, R., 2017. The role of public and private natural space in children's social, emotional and behavioural development in Scotland: A longitudinal study. Environ. Res. 158, 729-736. doi:10.1016/j.envres.2017.07.038 
Rybarczyk, G., Wu, C., 2010. Bicycle facility planning using GIS and multi-criteria decision analysis. Appl. Geogr. 30, 282-293. doi:https://doi.org/10.1016/j.apgeog.2009.08.005

Seiferling, I., Naik, N., Ratti, C., Proulx, R., 2017. Green streets - Quantifying and mapping urban trees with street-level imagery and computer vision. Landsc. Urban Plan. 165, 93101. doi:10.1016/j.landurbplan.2017.05.010

Seto, K.C., Fragkias, M., Güneralp, B., Reilly, M.K., Pidgeon, A., 2011. A Meta-Analysis of Global Urban Land Expansion. PLoS One 6, e23777. doi:10.1371/journal.pone.0023777

Shahabi, K., Wilson, J.P., 2018. Scalable evacuation routing in a dynamic environment. Comput. Environ. Urban Syst. 67, 29-40. doi:https://doi.org/10.1016/j.compenvurbsys.2017.08.011

Su, J.G., Winters, M., Nunes, M., Brauer, M., 2010. Designing a route planner to facilitate and promote cycling in Metro Vancouver, Canada. Transp. Res. Part A Policy Pract. 44, 495505. doi:https://doi.org/10.1016/j.tra.2010.03.015

Sui, D., 2014. Opportunities and impediments for open GIS. Trans. GIS 18, 1-24. doi:10.1111/tgis.12075

Takebayashi, H., Kasahara, M., Tanabe, S., Kouyama, M., 2017. Analysis of Solar Radiation Shading Effects by Trees in the Open Space around Buildings. Sustainability 9, 1398. doi:10.3390/su9081398

Walk Score ${ }^{\circledR}$, n.d. Get Your Walk Score [WWW Document]. URL https://www.walkscore.com/ (accessed 2.23.18).

Wei, Y., Xiaoguang, Y., 2013. A totally Astar-based multi-path algorithm for the recognition of reasonable route sets in vehicle navigation systems. Procedia - Soc. Behav. Sci. 96, 10691078. doi:10.1016/J.SBSPRO.2013.08.123

Wong, B.Y., Faulkner, G., Buliung, R., 2011. GIS measured environmental correlates of active school transport: a systematic review of 14 studies. Int J Behav Nutr Phys Act 8. doi:10.1186/1479-5868-8-39

Zafra, I., 2017. Ciudades aptas para escolares. El País. 
Žlender, V., Ward Thompson, C., 2017. Accessibility and use of peri-urban green space for inner-city dwellers: A comparative study. Landsc. Urban Plan. 165, 193-205. doi:10.1016/j.landurbplan.2016.06.011

\section{Acknowledgements}

We thank Gema Zarrías Martos, the Technical Topography Engineer, for her participation in developing this project. The authors also wish to thank the European Commission for supporting the project MySmart School, with Ref. 2015-1-FR01-KA201-015274 in the KA201 programme of strategic actions in Primary Education through those people who participated in this project: the public Vicente Blasco Ibáñez school, the Alginet Town Council and the Universidad Politécnica de Valencia (UPV). We particularly thank: (i) the management team, the collaborators from the school's Mother and Fathers Association, the tutors and students of grade 5 and 6 students from the public Vicente Blasco Ibáñez School in Alginet, especially for their enthusiasm, direct implication and active participation in this project; (ii) the Alginet Town Council for supporting the project and for implementing the proposed improvements; (iii) the UPV research team for its collaboration, help and for providing ideas. 